\title{
Harnessing big data for estimating the energy consumption and driving range of electric vehicles
}

Fetene, Gebeyehu Manie; Kaplan, Sigal; Mabit, Stefan Lindhard; Jensen, Anders Fjendbo; Prato, Carlo Giacomo

\section{Published in:}

Transportation Research. Part D: Transport \& Environment

Link to article, DOI:

10.1016/j.trd.2017.04.013

Publication date:

2017

Document Version

Peer reviewed version

Link back to DTU Orbit

Citation (APA):

Fetene, G. M., Kaplan, S., Mabit, S. L., Jensen, A. F., \& Prato, C. G. (2017). Harnessing big data for estimating the energy consumption and driving range of electric vehicles. Transportation Research. Part D: Transport \& Environment, 54, 1-11. https://doi.org/10.1016/j.trd.2017.04.013

\section{General rights}

Copyright and moral rights for the publications made accessible in the public portal are retained by the authors and/or other copyright owners and it is a condition of accessing publications that users recognise and abide by the legal requirements associated with these rights.

- Users may download and print one copy of any publication from the public portal for the purpose of private study or research.

- You may not further distribute the material or use it for any profit-making activity or commercial gain

- You may freely distribute the URL identifying the publication in the public portal 


\section{Harnessing big data for estimating the energy consumption and driving range of electric vehicles}

Gebeyehu M. Fetene $^{\text {a }}$, Sigal Kaplan ${ }^{\mathrm{ab}}$, Stefan L. Mabit ${ }^{\mathrm{a}}$, Anders F. Jensen ${ }^{\mathrm{a}}$, Carlo G. Prato ${ }^{\mathrm{*}}$

${ }^{a}$ Department of Management Engineering, Technical University of Denmark

Bygningstorvet 116B, 2800 Kgs. Lyngby, Denmark

${ }^{\mathrm{b}}$ Department of Geography, Hebrew University of Jerusalem

Mount Scopus, 91905 Jerusalem, Israel

c School of Civil Engineering, The University of Queensland

St. Lucia 4072, Brisbane, Australia

* corresponding author

School of Civil Engineering, The University of Queensland

St. Lucia 4072, Brisbane, Australia

Tel: +61.7.33651569, email: c.prato@uq.edu.au 


\begin{abstract}
Analyzing the factors that affect the energy efficiency of vehicles is crucial to the overall improvement of the environmental efficiency of the transport sector, one of the top polluting sectors at the global level. This study analyses the energy consumption rate (ECR) and driving range of battery electric vehicles (BEVs) and provides insight into the factors that affect their energy consumption by harnessing big data from real-world driving. The analysis relied on four data sources: (i) driving patterns collected from 741 drivers over a two-year period; (ii) drivers’ characteristics; (iii) road type; (iv) weather conditions. The results of the analysis measure the mean ECR of BEVs at $0.183 \mathrm{kWh} / \mathrm{km}$, underline a 34\% increase in ECR and a 25\% decrease in driving range in the winter with respect to the summer, and suggest the electricity tariff for BEVs to be cost efficient with respect to conventional ones. Moreover, the results of the analysis show that driving speed, acceleration and temperature have non-linear effects on the ECR, while season and precipitation level have a strong linear effect. The econometric model of the ECR of BEVs suggests that the optimal driving speed is between 45 and $56 \mathrm{~km} / \mathrm{h}$ and the ideal temperature from an energy efficiency perspective is $14^{\circ} \mathrm{C}$. Clearly, the performance of BEVs highly depends on the driving environment, the driving patterns, and the weather conditions, and the findings from this study enlighten the consumers to be more informed and manufacturers to be more aware about the actual utilization of BEVs.
\end{abstract}

Keywords: battery electric vehicles; big data; energy consumption rate; driving range; driving environment. 


\section{Introduction}

As the transport sector is one of the largest contributors of greenhouse gases at the global level (see, e.g., Alessandrini et al., 2012; Zahabi et al., 2014), there have been efforts by car manufacturers, car drivers and governments to improve fuel consumption efficiency, reduce pollution and limit dependence on fossil fuel. For example, some EU and US governments have set standards that limit the pollution level of cars and have used incentives and taxes to induce car manufacturers to produce, and car users to drive, fuel-efficient vehicles (Kono et al., 2008). Battery electric vehicles (BEVs) are considered as one alternative to curtail pollution from the transport sector and to reduce dependence on the scarce and highly pollutant petroleum since the electricity needed to charge BEVs can be obtained from renewable energy resources such as wind, solar power and hydro.

However, the market penetration rate of BEVs is lethargic, mainly because of high purchase prices, limited recharging infrastructures, limited driving range coupled with long recharging times, uncertainties concerning driving range and battery life, and risk aversion behavior in adopting new technologies (see, e.g., Birrell et al., 2014; Egbue and Long, 2012; Kihm and Trommer, 2014). It is clear that uncertainty plays a significant role in the (non-)choice of BEVs, especially when thinking about the driving range and the refueling costs and time with respect to a conventional car. Uncertainty plays an even larger role when factoring in that customers have limited knowledge about the actual performances of BEVs and their sensitivity to driving environments, with this lack of knowledge adversely affecting the demand for BEV (Birrell et al., 2014; Jensen et al., 2013). Accordingly, providing insight into the factors that affect the energy consumption rate (ECR) and driving range of BEVs under different driving environments is very relevant to support on the one hand consumers in choosing appropriate 
vehicles that suit their needs and, on the other hand, manufacturers in distinguishing and targeting different customers depending on the driving environments that the customers live and travel in.

Insights into the factors that affect the ECR and information about the driving range of conventional cars have been provided extensively, as their fuel consumption is well-documented in both the theoretical literature (Mellios et al., 2011; Nam and Giannelli, 2005) and the empirical literature (Brundell-Freij and Ericsson, 2005; Ericsson, 2001; Hu et al., 2012). Existing studies showed that the fuel consumption rate of conventional cars is affected by road width (Brundell-Freij and Ericsson, 2005; Hu et al., 2012; Kono et al., 2008; Yao et al., 2007), road grade (Nam and Giannelli, 2005; Wang et al., 2008), traffic congestion and speed limits (Brundell-Freij and Ericsson, 2005), as well as by traffic information provided to drivers (Fotouhi et al., 2014; Kono et al., 2008). Existing studies also illustrated that driving patterns (in terms of speed and acceleration profiles) are the main factors affecting fuel consumption of conventional cars (El-Shawarby et al., 2005; Ericsson, 2001; Heide and Mohazzabi, 2013; Nesamani and Subramanian, 2006; Wang et al., 2008). Moreover, a number of studies have provided mathematical and technical detailed accounts of the effects of different car characteristics on the fuel consumption of conventional cars (see, e.g., Brundell-Freij and Ericsson, 2005; Heide and Mohazzabi, 2013; Nam and Giannelli, 2005; U.S.E.P.A., 2014). It should be noted that the effects of car features on fuel consumption are usually taken into account during the design of the vehicle by the manufacturers, and are usually made available to the consumers during the purchase of the vehicle (Ben-Chaim et al., 2013; Kono et al., 2008). Insights into the factors that affect the ECR of hybrid electric vehicles (HEVs) using both fuel and rechargeable batteries have been provided to a lesser extent. For example, winter has 
been related to a decrease of $20 \%$ in the fuel efficiency of HEVs, and their overall fuel economy with respect to conventional cars has been evaluated as possibly overweighed by the poor performance of HEVs in cold weather locations (Zahabi et al., 2014). Temperature has been found as relevant in other studies that have focused also on the driving environment (Alvarez and Weilenmann, 2012; Fontaras et al., 2008; Lohse-Busch et al., 2013), while the power ratio of HEV components and the applied control strategy of HEVs have been demonstrated analytically related to their ECR (Banjac et al., 2009).

Insights into the factors that influence the ECR of BEVs have been provided scarcely, mainly because of their recent market penetration. Most studies included technical analyses that investigated the effects of car components on the ECR (see, e.g., Duke et al., 2009) and analyses by car manufacturers and other stakeholders. Large differences were usually observed between the results of car manufacturers and the results observed in real-world (Huo et al., 2011), mainly because manufacturers test BEVs by performing a long and continue test drive from a fully charged battery to a completely flat battery, thus ignoring basic real-world energy expenditures such as the energy used to overcome the inertia force to propel a parked car and the energy used to cool down a car during each trip. A limited number of studies have focused on the ECR and the driving range of BEVs: the ECR of BEVs was evaluated by comparing the driving range reported by the manufacturer versus the actual driving range of drivers (Birrell et al., 2014); the ECR of BEVs was estimated by taking into account driving patterns and car features from GPS data, and in-city driving was deemed more energy efficient than freeway driving (Wu et al., 2015). However, these studies present limitations: (i) the study samples consisted respectively of one (Wu et al., 2015) and 11 drivers (Birrell et al., 2014), with obvious consequences on the possibility of generalizing any finding; (ii) the data collections did not cover the winter months, 
with obvious consequences on the possibility of analyzing the effect of cold temperature on the ECR of BEVs; (iii) the data analyses did not control for possible confounders, with obvious consequences on the possibility of assessing whether the ECR differences were caused by other factors.

As aforementioned, the uncertainty and the consequent anxiety about the driving range and the energy consumption of BEVs is one of the major barriers to their wider market penetration. It is therefore essential to provide insights into the actual ECR and driving range of BEVs under different driving environments as well as the factors that affect them while controlling for drivers' characteristics, weather variations, spatial areas, and road characteristics. The current study fills this gap by analyzing real-world data collected over a two-year period in Denmark, namely by addressing questions about the ECR of BEVs under various driving environments, the sensitivity of BEVs to speed and acceleration profiles, the optimal speed for the most energy efficient use of BEVs, the variability in the performances of BEVs with varying factors such as speed, wind, temperature, and location. Addressing these questions could help customers not only in reducing the uncertainty about energy consumption and driving range because of the provided information, but also in adopting optimal driving patterns for energy efficient driving.

Big data were used for providing answers to these questions, as more than a quarter of a million trips performed by $741 \mathrm{BEV}$ drivers were analyzed in the current study. The data were collected over a two-year period between January 2012 and January 2014 by Clever A/S, an electric mobility operator in Denmark using three models of BEVs, namely Citroen C-Zero, Peugeot Ion and Mitsubishi iMiev. The data contained information for each trip about vehicle positioning (i.e., longitude, latitude), driving patterns (i.e., speed profile, acceleration profile), 
battery charge level, time and duration of the trip, and road characteristics after map-matching. Data included also information about the weather conditions during each trip as well as the driver characteristics as reported by drivers while renting the BEV. The analysis focused on the computation of the ECR and the corresponding driving range of BEVs from the large sample of trips in real-world driving conditions, and the assessment of the effects of driving patterns, road characteristics and weather conditions on the ECR of BEVs from the estimation of individualspecific fixed effects econometric models. Moreover, the analysis proposed a simple formula that allows consumers to compare BEVs and conventional cars in terms of fuel (electricity) cost under varying intensity of the winter season. The current study contributes to the literature about energy efficiency of BEVs by overcoming limitations of existing studies: (i) the sample of the study is significantly larger than previous studies with about 2.3 million km driven; (ii) the seasonal variation is accounted for, as the study period covers two summers and three winters; (iii) the weather effects are considered, as the study looks at the effect of temperature, precipitation and wind speed; (iv) the actual driving patterns are analyzed, as the speed and acceleration profiles are collected for each trip; (v) econometric models are used to disentangle the effect of each variable on the ECR after controlling for possible confounders.

The remainder of this paper is structured as follows. The next section presents the data collection and the methods used to compute the ECR of BEVs and estimate the model of the ECR variation. Then, the results of the computation and the estimation are presented, and conclusions and further research directions are offered in the last section. 


\section{Methods}

\subsection{Data Collection}

Four data sources were used for this paper: (i) driving patterns collected from GPS data loggers installed on 200 BEVs used by 741 drivers for 276,102 trips and about 2.3 million km travelled; (ii) drivers’ characteristics obtained upon registration and reception of the BEVs for 3 to 6 months; (iii) road characteristics collected from map-matching the GPS data to the Danish road network; (iv) weather information obtained from the Danish Meteorological Institute (DMI).

Clever A/S collected the driving pattern data from customers who have been driving BEVs for a period of 3 to 6 months in a project called "test-en-elbil” (in English: "test an electric car”) where Danish drivers were invited to drive BEVs and were proposed an agreement to collect information about their trips during the period. The data were collected using GPS devices during the period from January 2012 to January 2014, and the GPS data loggers were mounted on three fully BEV models, namely Citroen C-Zero, Peugeot Ion, and Mitsubishi iMievst, which are actually produced by the same manufacturer and are practically identical. Variables related to driving patterns (i.e., speed profiles, acceleration profiles), date and time of each trip, distance and duration of each trip, geographical coordinates of each trip, and percentage change in the battery charge level for each trip, were extracted from the GPS data. Time-of-day periods and seasonal variation were defined on the basis of the date and time stamps of the GPS loggers.

Variables related to income and demographic characteristics (age and gender) of drivers were collected during the registration process for testing the BEVs. The drivers were mainly men 
(56\%), with average age of about 44 years old, and heterogeneous distribution of income as $48 \%$ declared a yearly income higher than the mean national income.

Controlling for the road and traffic characteristics revealed cumbersome since road grade and traffic congestion vary even within a trip. However, after map-matching the GPS data to the Danish road network for each trip, it was considered that road grade is not relevant to Denmark as one of the flattest countries in the world, and rush hour is a relevant proxy to traffic congestion hours. Moreover, it was discerned whether each trip was performed on a highway in order to account for road type.

Controlling for the weather conditions revealed also cumbersome because weather varies dynamically across time and location even for a single trip. It was considered that a driver could experience different types and level of weather conditions, but the changes would have marginal effects when considering that most trips in Denmark are rather short. Accordingly, and similarly to existing literature, the mean values for temperature, precipitation, wind speed and visibility of each trip as reported by DMI were considered for each trip.

Considering the initially registered 276,102 trips, the data cleaning process implied looking for missing values and possible errors in the variables. In particular, 10,977 trips had missing information about the battery charge level, 10,420 trips had unreliable information with extremely low or high values of battery charge level variation, and 9,394 trips had missing information concerning the identity of the driver. Following the data cleaning process, the data analysis focused on 239,247 trips for the descriptive part and 229,853 trips for the regression part. 


\subsection{Data analysis}

\subsubsection{Descriptive analysis of BEV performance}

Initially, this study examined the performance of BEVs in terms of ECR (analogous to the fuel consumption rate for conventional cars). Namely, the ECR was calculated as the ratio between the power consumed and the distance traveled for different models and different driving environments:

$$
\text { ECR }=\frac{\text { Power consumed }(\mathrm{kWh})}{\text { Distance traveled }(\mathrm{km})}
$$

The lower is the ECR, the better is the energy efficiency. In this study, the data contained the percentage change in battery charge level before and after each trip, which implied that the value obtained from the data collection had to be multiplied by the Wh capacity of the battery of the vehicle (i.e., $16 \mathrm{kWh}$ ) in order to obtain the power consumed in $\mathrm{kWh}$.

Given the ECR, the driving range of BEVs was computed as follows:

$$
\text { Driving Range }=\frac{\text { Power of a fully charged BEV }(\mathrm{kWh})}{\text { ECR }(\mathrm{kWh} / \mathrm{km})}
$$

It should be noted that the driving range depends on the battery capacity, the car performance, or both. Accordingly, a higher driving range would not necessarily indicate that the BEV performs better in terms of ECR, but could possibly relate to a higher battery capacity that comes at a heftier price. For this reason, comparing ECR between BEVs provides more correct insight into the energy efficiency of BEVs.

\subsubsection{Modeling analysis of the ECR of BEVs}

Explaining the factors that affect the ECR of BEVs under different driving environments is relevant to consumers for choosing vehicles that suit their driving needs and to manufacturers for distinguishing and targeting market segments according to their driving environments. 
Accordingly, this study provides the estimation of a model that unravels the sign and magnitude of the factors that affect the variation of the ECR of BEVs.

An unobserved effects model was used because this is the most suitable model for panel data as the ones collected in this study (Wooldridge, 2000). In fact, considering unobserved (latent) individual-specific effects allows controlling for unobservable factors such as car maintenance (e.g., oil, brakes), weight load, and usage of car devices that could affect energy consumption, which are less likely to vary for an individual while they certainly vary across individuals. Accordingly, an unobserved individual specific effect model was estimated to explain the ECR variation. A general trip-based model that can be used to estimate the factors explaining the variation of the ECR is given by:

$$
E C R_{i t}=\theta_{t}+X_{i} \beta+W_{i t} \alpha+Y_{i t} \delta+Z_{i t} \gamma+\phi_{i}+v_{i t}
$$

where $E C R_{i t}$ is the ECR of a trip by driver $i$ at time $t, \theta_{t}$ denotes a time-varying intercept, $X_{i}$ is a row vector of the characteristics of the vehicle used by driver $i, W_{i t}$ is a row vector of weather variables that vary across driver $i$ and time $t, Y_{i t}$ is a row vector of road characteristics that vary across individuals $i$ and time $t, Z_{i t}$ is a row vector of household characteristics that could vary across individuals $i$ and within a household across time $t, \phi_{i}$ is individual-specific unobserved effect that is time-invariant, $v_{i t}$ is the idiosyncratic error term with mean zero and is uncorrelated with any of the explanatory variables, and the column vectors $\alpha, \beta, \gamma$ and $\delta$ contain the parameters to be estimated. It should be noted that the model is trip-based and a subscript for each trip has been omitted to simplify the notation.

The choice of the appropriate model among unobserved effects models mainly depends on how $\phi_{i}$ is correlated with the explanatory variables. The random effects model is preferred to fixed effects model when $\phi_{i}$ is uncorrelated with explanatory variables, and when the main 
variables of interest are dummies. Conversely, the fixed effects model is preferred when there is strong correlation between the unobserved factors and the explanatory variables included in the model, since the unobserved time-invariant variable will be effectively concealed out by timedemeaning in the fixed effects model. One way of choosing between random and fixed effects models is to conduct a Hausman test (Wooldridge, 2010). Having found that the fixed effects model is preferred to random effects model via a Hausman test for the data collected in this study, a fixed effects model was estimated to investigate the factors that explain the variation of ECR. Correspondingly, the explanatory variables $X_{i}$ and $Z_{i t}$, as well as the unobserved effect $\phi_{i}$, were canceled out by time-demeaning given that these variables did not vary over the period in which the data were collected. Accordingly, the estimated was given by:

$$
E C R_{i t}-\overline{E C R}_{i}=\theta_{t}-\bar{\theta}+\left(W_{i t}-\bar{W}_{i}\right) \tilde{\alpha}+\left(Y_{i t}-\bar{Y}\right) \tilde{\delta}+v_{i t}-\bar{v}_{i}
$$

where the bars over each corresponding variable denote the mean of that variable computed over

time (for example, $\overline{E C R}_{i}=\frac{1}{T} \sum_{t} E C R_{i t}, \bar{W}_{i}=\frac{1}{T} \sum_{t} W_{i t}$ ). This transformation enables to cancel

out the unobserved effect $\phi_{i}$ that could affect the estimation result otherwise, and the model provides consistent estimates regardless of the correlation between $\phi_{i}$ and the explanatory variables (Wooldridge, 2010). IT should be noted that the fixed effects model enables to control for unobserved activities of drivers corresponding to driving BEVs (e.g., weight loaded, usage of car devices, car maintenance) that could otherwise bias the estimates.

\section{Results}

In this section, the results from the data analyses are presented, namely the descriptive statistics results about the trips and the ECR and the parameter estimates from the fixed effects model explaining the variation of the ECR of BEVs. 


\subsection{Overview of trips by BEVs}

On average, each driver performed 307.1 trips during 90.7 days where the individuals used BEVs. Concerning the length of the trips, about $50 \%$ of them were less than $5 \mathrm{~km}$, and only about $1 \%$ of them were over $50 \mathrm{~km}$. A possible reason for the short trip distances could be the fact that about 39\% of Danes commuted less than $5 \mathrm{~km}$ in 2013 (Denmark Statistics, 2014), and another reason could be that the drivers had a range anxiety problem and used the BEV for shorter distances.

Given the average short distances, it is not surprising that a great share of drivers did not recharge the BEVs upon arrival from each trip. It is however interesting that the infrequent recharging did not correspond to waiting for having an empty battery: the mean and the median of battery charge when the recharging was performed were equal respectively to $55.5 \%$ and 56.0\%, namely individuals recharged their BEVs well before risking to have their batteries empty.

Figure 1 presents the kernel density of the frequency of trips with the BEVs in the sample according to the departure time of the trips. The figure shows that most of the weekday trips were performed during the peak hours in the morning (i.e., $7.00 \mathrm{am}-8.30 \mathrm{am}$ ) and the afternoon (i.e., $3.00 \mathrm{pm}-5.30 \mathrm{pm}$ ), which suggests that the time-of-day patterns of the trips with the BEVs are not dissimilar from the ones of the general population when looking at data from the Danish National Travel Survey. The same applies also to the weekends, as most of the weekend trips were performed between 9.00 am and $5.00 \mathrm{pm}$. 


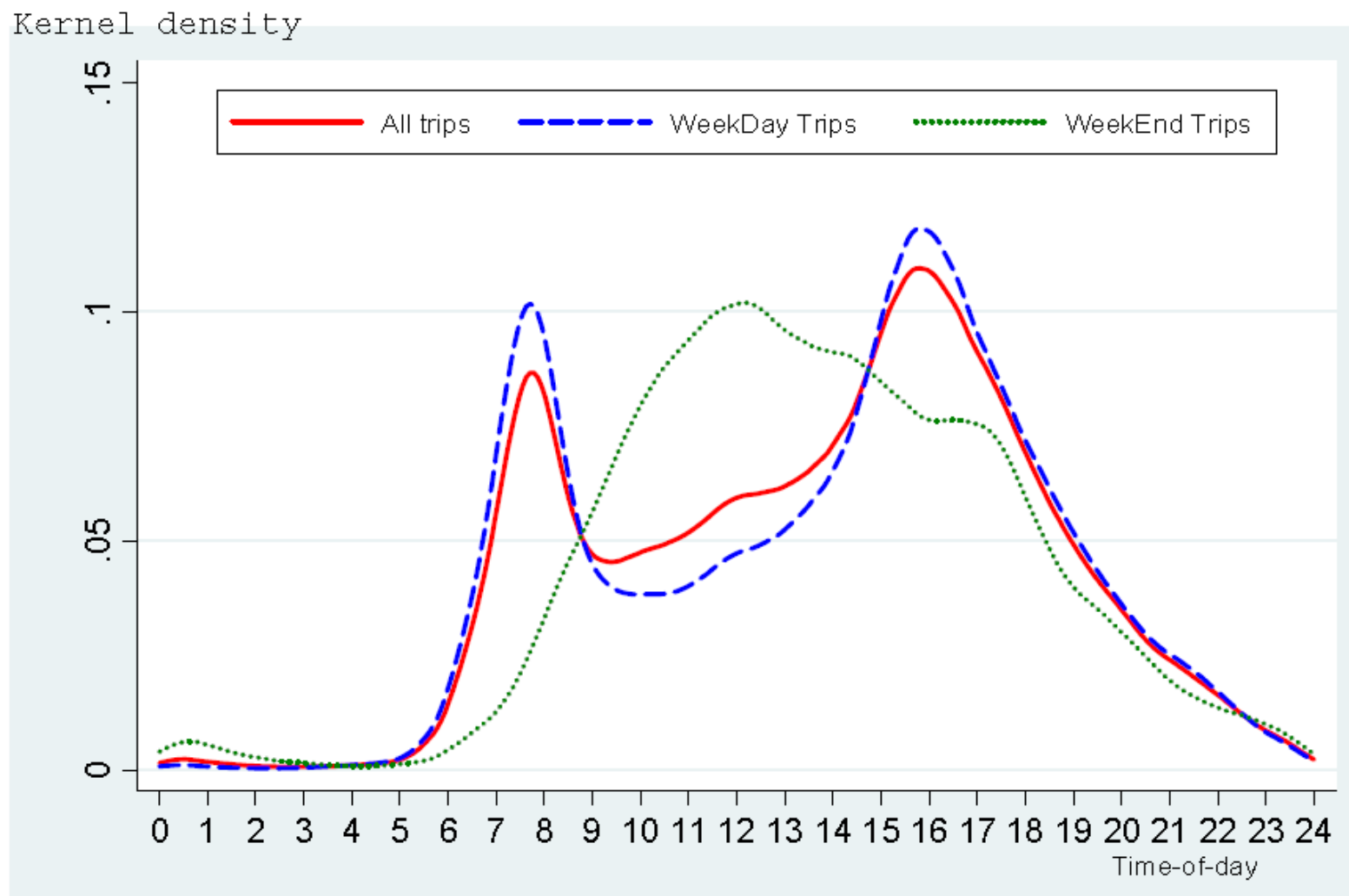

Figure 1. Departure time of trip by BEVs, kernel density

\subsection{Observed ECR of BEVs}

\subsubsection{Overall ECR}

The mean ECR in the sample is equal to $0.183 \mathrm{kWh} / \mathrm{km}$, namely each $\mathrm{km}$ traveled consumes on average $183 \mathrm{Wh}$ and hence a minimum power of $9.125 \mathrm{KWh}$ must be available for a trip of $50 \mathrm{~km}$ not requiring recharging of the battery.

Figure 2 presents the distribution of the ECR from the 239,247 trips in the analyzed data. The vertical line at $125 \mathrm{Wh} / \mathrm{km}$ denotes the mean ECR from the manufacturer specification of the BEVs in the sample, whereas the vertical line at $183 \mathrm{Wh} / \mathrm{km}$ denotes the mean ECR from the observation of the data. The resulting driving range is about $25.5 \%$ lower than the driving range reported in the manufacturer specification of the BEV models used in this study. Figure 2 shows that the distribution of the ECR presents high heterogeneity and indicates that BEVs consume 
more energy per distance unit than reported by manufacturers since a massive share is clearly over the manufacturer specification. A reason for the difference is likely that the testing conditions of manufacturers do not include the energy consumed to propel a parked vehicle or to cool down a vehicle during each real-world trip. Another reason for the difference and the heterogeneity is possibly the difference in driving environment whose investigation motivated the modeling of the variation of the ECR presented later.

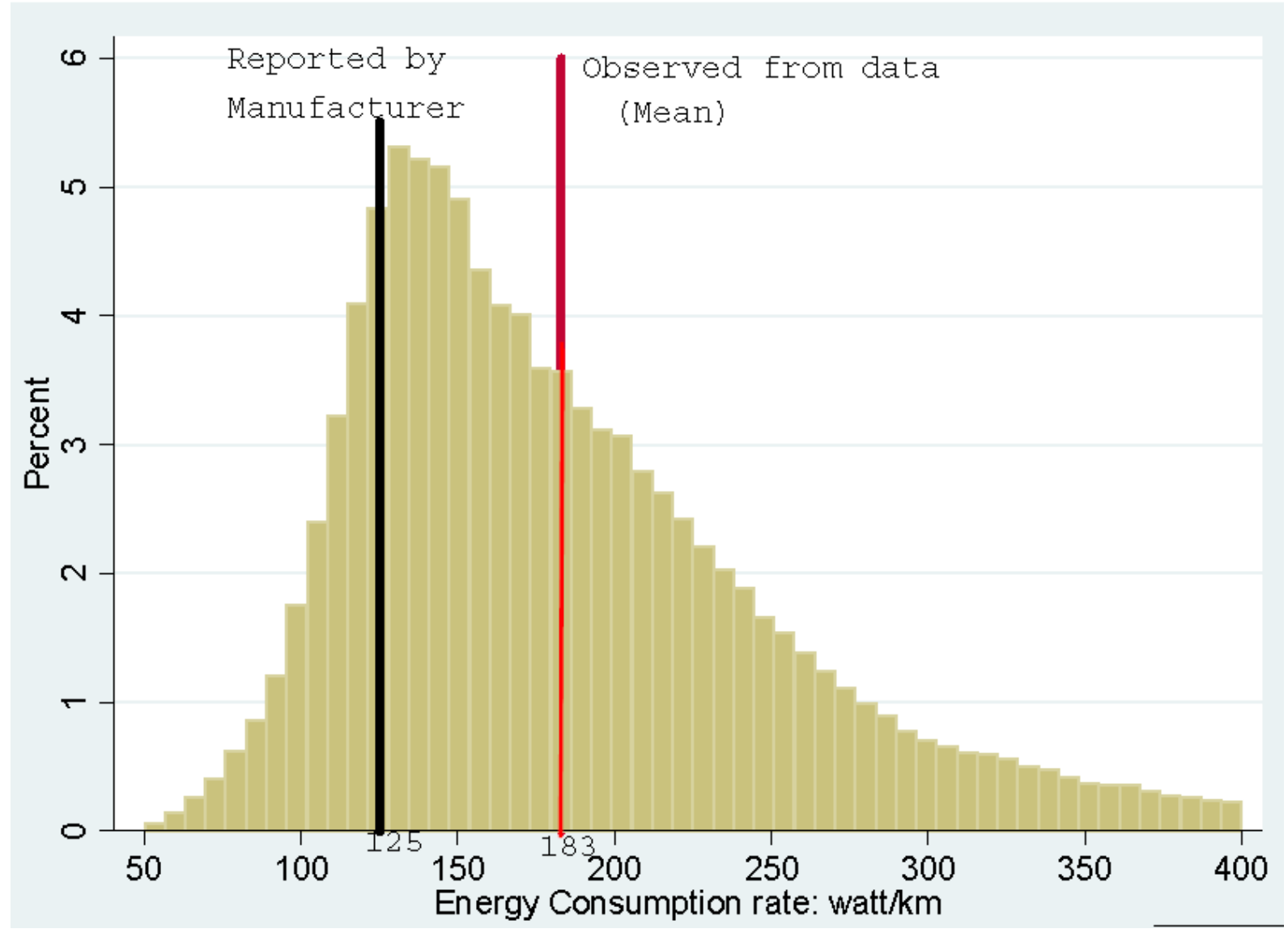

Figure 2. ECR distribution and observed versus reported ECR of BEVs

\subsubsection{ECR by season}

The ECR was computed for the summer and the winter seasons, and results showed that ECR is higher and consequently the driving range is shorter in winter with respect to summer: the average ECR is equal to $0.168 \mathrm{kWh} / \mathrm{km}$ during the summer and $0.225 \mathrm{kWh} / \mathrm{km}$ during 
winter, with an observed 34\% increase in consumption per km driven in winter. Both a parametric t-test and a non-parametric Mann-Whitney test proved the difference to be statistically significant, and the difference is higher than the $20 \%$ reported in Canada for HEVs (Zahabi et al., 2014).

Figure 3 presents the Box and Whisker plots of the distributions of the summer and winter ECR. The plots display mean variations non-parametrically: the filled-in boxes represent the interquartile ECR where the intermediate line denotes the median, while the whiskers represent the outliers. Figure 3 shows that, even when the distribution of the ECR over the seasons is accounted for, the ECR in summer is lower than in winter as median ECR in summer (marginally higher than 150) is lower than the median of the ECR in winter (higher than 250).

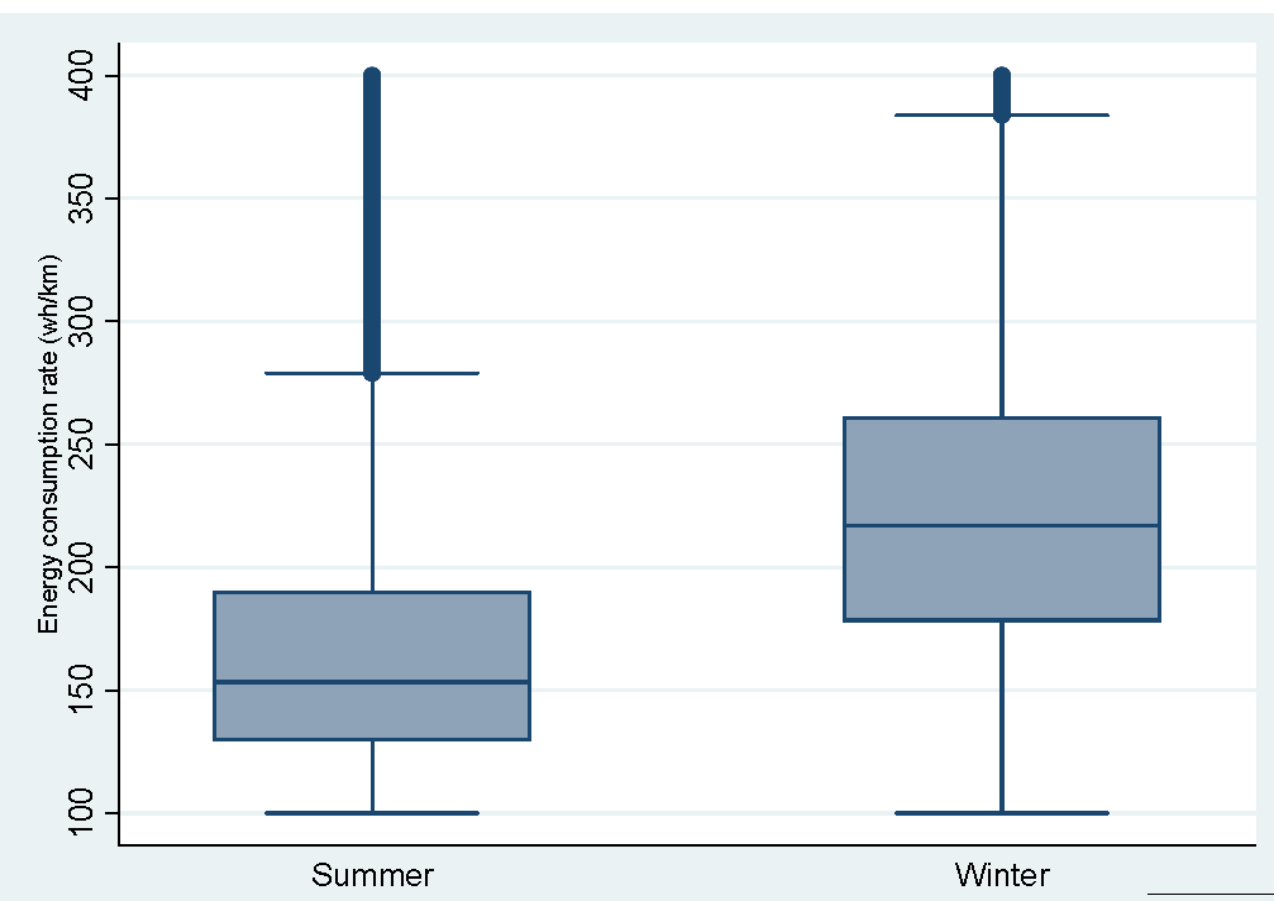

Figure 3. Winter versus summer Box-WHISKER plots of THE ECR of BEVs

\subsubsection{ECR by trip distance}

As driving patterns could vary with trip distance (Fosgerau, 2005), and in turn the distance could affect the ECR (Ericsson, 2001), it is relevant to consider the ECR for different 
trip distances in order to know for which trip distances BEVs are more energy efficient. The distribution of the distances in the trips analyzed in this study suggested considering short trips (less than $2 \mathrm{~km}$ ), medium trips (between 2 and $10 \mathrm{~km}$ ) and long trips (longer than $10 \mathrm{~km}$ ).

Table 1 presents the mean, median and percentiles of the distributions of ECR and driving range for the three trip distance bands considered. Obviously, it emerges that the mean ECR decreases (and consequently the mean driving range increases) with the increase of the trip distance: for example, in average short trips consume $40 \mathrm{Wh} / \mathrm{km}$ more than medium trips and 57 $\mathrm{Wh} / \mathrm{km}$ more than long trips. The difference is observed for all percentiles except the lower one, and it is statistically significant according to both a parametric t-test and a non-parametric MannWhitney test. Roughly speaking, these findings suggest that BEVs are more energy-efficient for individuals with relatively longer commuting distance rather than ones with shorter commuting distance.

Table 1. ECR and driving range of BEVs by trip distance

\begin{tabular}{lrrrrrr}
\hline & \multicolumn{2}{c}{ Short Trips $(<2 \mathrm{~km})$} & Medium Trips $(\geq 2 \mathrm{~km} \&<$ & \multicolumn{2}{c}{ Long Trips $(\geq 10 \mathrm{~km})$} \\
\hline & ECR & Driving & $\begin{array}{r}\text { ECR } \\
(\mathrm{Wh} / \mathrm{km})\end{array}$ & $\begin{array}{r}\text { Driving } \\
\text { range }(\mathrm{km})\end{array}$ & $\begin{array}{r}\text { ECR } \\
(\mathrm{Wh} / \mathrm{km})\end{array}$ & $\begin{array}{r}\text { Driving } \\
\text { range }(\mathrm{km})\end{array}$ \\
Mean & 223 & 82 & 183 & 96 & 166 & 102 \\
5 percentile & 112 & 143 & 111 & 144 & 114 & 141 \\
25 percentile & 162 & 99 & 136 & 117 & 134 & 119 \\
Median & 209 & 76 & 169 & 95 & 159 & 101 \\
75 percentile & 281 & 57 & 222 & 72 & 192 & 83 \\
95 percentile & 366 & 44 & 298 & 54 & 238 & 67 \\
Standard dev. & 79 & 30 & 59 & 28 & 39 & 23 \\
No. obs. & & 54,161 & & 108,605 & & 73,809 \\
\hline
\end{tabular}




\subsubsection{ECR by road type}

As road characteristics have an effect on the fuel economy of conventional and hybrid vehicles (Brundell-Freij and Ericsson, 2005; Ericsson, 2001; Zahabi et al., 2014), ECR was computed for highway and non-highway trips.

Table 2 presents the mean, median and percentiles of the distributions of ECR and driving range for the two road types considered. No clear difference emerges between driving on highway or non-highway roads, although the average ECR is slightly lower for highway portions of the trips. More specifically, while the $5^{\text {th }}$ and $25^{\text {th }}$ percentiles of the ECR of trips on highway are higher (and consequently the driving ranges are shorter), the opposite is observed when looking at the mean, median, $75^{\text {th }}$ and $95^{\text {th }}$ percentile of the ECR of BEVs. The differences are however not statistically significant according to both a parametric t-test and a non-parametric Mann-Whitney test.

Table 2. ECR and driving range of BEVs by road type

\begin{tabular}{lrrrr}
\hline & \multicolumn{2}{c}{ Trips on highway } & \multicolumn{2}{c}{ Trips not on highway } \\
& ECR $(\mathrm{Wh} / \mathrm{km})$ & $\begin{array}{r}\text { Driving range } \\
(\mathrm{km})\end{array}$ & ECR $(\mathrm{Wh} / \mathrm{km})$ & $\begin{array}{r}\text { Driving range } \\
(\mathrm{km})\end{array}$ \\
\hline Mean & 174 & 96 & 187 & 94 \\
5 percentile & 121 & 132 & 111 & 144 \\
25 percentile & 145 & 111 & 138 & 116 \\
Median & 168 & 95 & 172 & 93 \\
75 percentile & 198 & 81 & 223 & 72 \\
95 percentile & 243 & 66 & 318 & 50 \\
Standard dev. & 39 & 21 & 63 & 29 \\
No. obs. & 16,369 & & & 210,984 \\
\hline
\end{tabular}




\subsection{Comparison of BEVs and conventional vehicles in terms of energy cost}

Having the mean ECR from the analyzed data allows formulating an equation for the (rough) comparison of BEVs and conventional vehicles in terms of fuel efficiency, at least in the Danish driving environments.

Consider that the mean ECR of BEVs in the analyzed sample is equal to $0.183 \mathrm{kWh} / \mathrm{km}$, and that the electricity tariff that the drivers pay for recharging their BEVs is equal to $P_{e}$ per KWh. Accordingly, the mean electricity cost per km traveled is equal to $0.183 P_{e}$. Consider that the mean fuel consumption per km traveled of a conventional car is equal to $v$, and that the fuel tariff that the drivers would pay for fueling the car is equal to $P_{f}$ per liter. Obviously, driving a $\mathrm{BEV}$ is cheaper than driving a conventional car in the case that the cost per $\mathrm{km}$ of the former $\left(0.183 P_{e}\right)$ is lower than the cost per km of the latter $\left(v P_{f}\right)$ :

$$
0.183 P_{e} \leq v P_{f}
$$

For example, if the fuel cost $P_{f}$ is equal to 11 DKK/liter (i.e., current price of petrol in Denmark) and the fuel consumption $v$ is equal to 0.05 liters (i.e., $20 \mathrm{~km} / \mathrm{liter}$ ), then it would be cheaper to drive a BEV if and only if the electricity tariff $P_{e}$ is not higher than $3 \mathrm{DKK} / \mathrm{kWh}$.

Consider a possible extension that differentiates the ECR into summer and winter seasons, and define the number of months $\theta$ with summer weather. Given the mean ECR for summer and winter computed from the analyzed data, it would be cheaper to drive a BEV rather than a conventional vehicle in terms of only running cost if and only if:

$$
0.168 P_{e}\left(\frac{\theta}{12}\right)+0.225 P_{e}\left(\frac{1-\theta}{12}\right) \leq \nu P_{f}
$$

It should be noted that more precision could be obtained by relating to the number of days rather than the number of months. 


\subsection{Modeling the variation of the ECR}

Table 3 presents the estimation results of the unobserved individual-specific fixed effects model that explains about $70 \%$ of the ECR variation between drivers, $28 \%$ of the ECR variation within drivers, and $42 \%$ of the ECR variation overall in the sample of 229,853 trips. Most of the explanatory variables are statistically significant and have the expected sign also when considering non-linearity in their relation to the ECR. The model estimates present effects on the ECR per km traveled, which means that the potential effects when considering yearly travel distances are considerably high.

Table 3. ECR model estimates

\begin{tabular}{lrrr}
\hline \hline Explanatory Variables & Estimate & standard error & p-value \\
\hline Mean driving speed & -19.000 & 0.365 & 0.0000 \\
Mean driving speed square & 0.761 & 0.015 & 0.0000 \\
Mean acceleration & 55.521 & 7.156 & 0.0000 \\
Mean acceleration square & 27.828 & 9.150 & 0.0020 \\
Trip distance & -1.110 & 0.062 & 0.0000 \\
Trip distance square & 0.010 & 0.001 & 0.0000 \\
Winter & 14.687 & 0.364 & 0.0000 \\
Highway & 0.534 & 0.381 & 0.1610 \\
Rush hour & -1.926 & 0.204 & 0.0000 \\
Battery level (at trip start) & 3.401 & 0.206 & 0.0000 \\
Battery level (at trip start) square & -0.056 & 0.003 & 0.0000 \\
Battery level (at trip start) cube & 0.000 & 0.000 & 0.0000 \\
Temperature & -4.807 & 0.040 & 0.0000 \\
Temperature square & 0.081 & 0.002 & 0.0000 \\
Wind speed & 0.695 & 0.042 & 0.0000 \\
Visibility & -0.118 & 0.005 & 0.0000 \\
Precipitation & 5.287 & 0.229 & 0.0000 \\
Constant & 135.489 & 6.378 & 0.0000 \\
\hline
\end{tabular}




\begin{tabular}{lcrr} 
R-square: within & 0.2714 & sigma_u & 20.0258 \\
R-square: between & 0.7020 & sigma_e & 44.8110 \\
R-square: overall & 0.4078 & rho & 0.1665 \\
Number of observations & & & 229,853 \\
\hline
\end{tabular}

Speed of driving and acceleration are extremely relevant to the ECR variation. The seasonal variation is proved to be associated with the ECR, and this finding is important because it shows that winter is positively related to an increase in ECR also when controlling for other variables including the weather conditions that are also associated with the ECR variation. It should be noted that the lower the ECR is, the better is the fuel efficiency, and thus statistically significant negative parameters in this model indicate which variables have a positive effect in terms of energy efficiency and driving range.

An interesting finding from the model estimation is that the mean driving speed presents a quadratic term, namely driving at both very slow and very fast speed increases the ECR (and, correspondingly, decreases driving range). A possible explanation for the slow speed relation could be associated with the energy required for keeping the BEV moving for a longer period, while a possible reason for the high speed relation could be linked to the energy required to speed up the BEV. To substantiate this finding, it was also run a locally weighted scatter plot smoothing estimation of the effect of speed of driving on ECR. Figure 4 presents a locally weighted scatterplot smoothing estimation of the effect of mean driving speed on the ECR of BEVs, where the horizontal axis represents the driving speed and the vertical axis represents the ECR. The model predicts that the energy saving driving speed is between 45 and $56 \mathrm{~km} / \mathrm{h}$ (minimum at about $52 \mathrm{~km} / \mathrm{h}$ ), which is lower than the fuel saving driving speed for conventional vehicles of 65 km/h (El-Shawarby et al., 2005). 


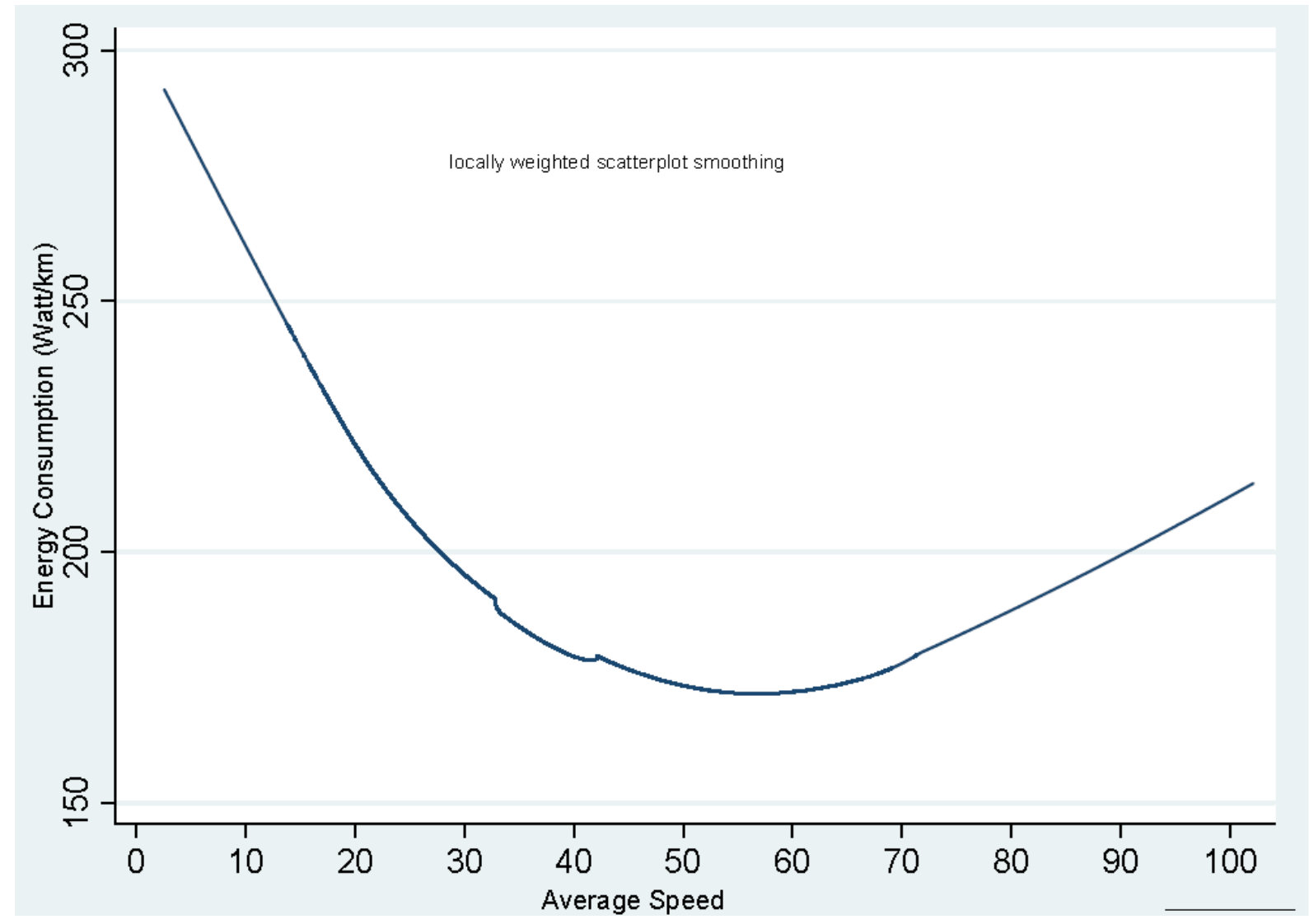

Figure 4. The effect of driving speed on the ECR of BEVs

Another interesting finding from the model estimation is the fact that the acceleration has an important effect on the ECR variation, and that this variation is positive for each unit increase in the acceleration, ceteris paribus. This finding is in line with another study looking at acceleration effect on the fuel consumption rate of conventional cars and HEVs (Zahabi et al., 2014), but there is a clear quadratic effect that has been ignored in previous studies.

The seasonal variation has a significant impact on the ECR, with a higher consumption of $15 \mathrm{Wh} / \mathrm{km}$ in winter with respect to summer, even when controlling for the weather effects such as temperature, precipitation, and wind. It is possible to assess the total effect of the winter season by taking the average values of the weather variables in the winter months and calculate the compound effect on the ECR, which suggests that the $15 \mathrm{Wh} / \mathrm{km}$ are a conservative estimate. 
Another interesting result from the model estimation is that the temperature has a nonlinear U-shaped effect on the ECR, namely driving at both too low and too high temperature affects negatively the energy efficiency of BEVs. This finding is not in line with the results reported by Birrell et al. (2014) that did not find any relation between temperature and driving range of BEVs, possibly because there was not enough variation in the temperature for a study conducted between May and October. This finding is however in line with the results presented by Lohse-Busch et al. (2013) that observed an increase of about 100\% in the ECR of BEVs in a controlled laboratory experiment with temperature falling from $70^{\circ} \mathrm{F}$ to $20^{\circ} \mathrm{F}$. It should be noted that previous studies did not consider non-linearity that appears intuitively relevant, as lower temperatures require more energy for warming the vehicle, and higher temperatures need more energy for cooling the vehicle. Ceteris paribus, the mode indicates that the most favorable temperature in terms of energy efficiency of BEVs is equal to $14{ }^{\circ} \mathrm{C}$.

Moreover, it is interesting that the initial level of the battery has a polynomial (third degree) effect on the ECR. Specifically, individuals can observe different rates of battery power consumption for driving in the same environment for the same distance, just because of a different battery charge level at the beginning of the trip. Figure 5 presents a locally weighted scatterplot smoothing estimation of the battery power depletion rate per km distance traveled, which was obtained by running-line least squares smoothing with 0.80 bandwidth (i.e., $80 \%$ of the observation is used to estimate each point of the curve). The graph reveals that the depletion rate of the battery power is polynomial, and the rate of depletion per km traveled is very high (mean value equal to $1.22 \%$ of the battery per km traveled) when the battery power is about $100 \%$ charged, then declines at a higher rate as the battery power decreases until the local minimum (equal to $1.17 \%$ per $\mathrm{km}$ ) when the battery power is about $77 \%$, and then gradually 
increases until the local maximum (equal to $1.2 \%$ per $\mathrm{km}$ ) after which the depletion rate is slow. It should be noted that the graph presents a magnified y-axis to appreciate the variation. The information from this graph could help BEV customers in having a better feeling for the range that they would be able to drive with the battery power they are left with. There is also the possibility that new BEV customers would be worried by observing that a fully charged battery drops very quickly after only a short drive.

Table 3 reveals also that, as expected, wind speed and precipitation have positive and statistically significant effect on ECR, whereas visibility (related to sunshine) has a positive and statistically significant effect on ECR. Driving on a highway does not seem to have a statistically significant effect on ECR. This may not be surprising since the main differences between driving on and off highway, namely the speed of driving and acceleration, are already controlled for.

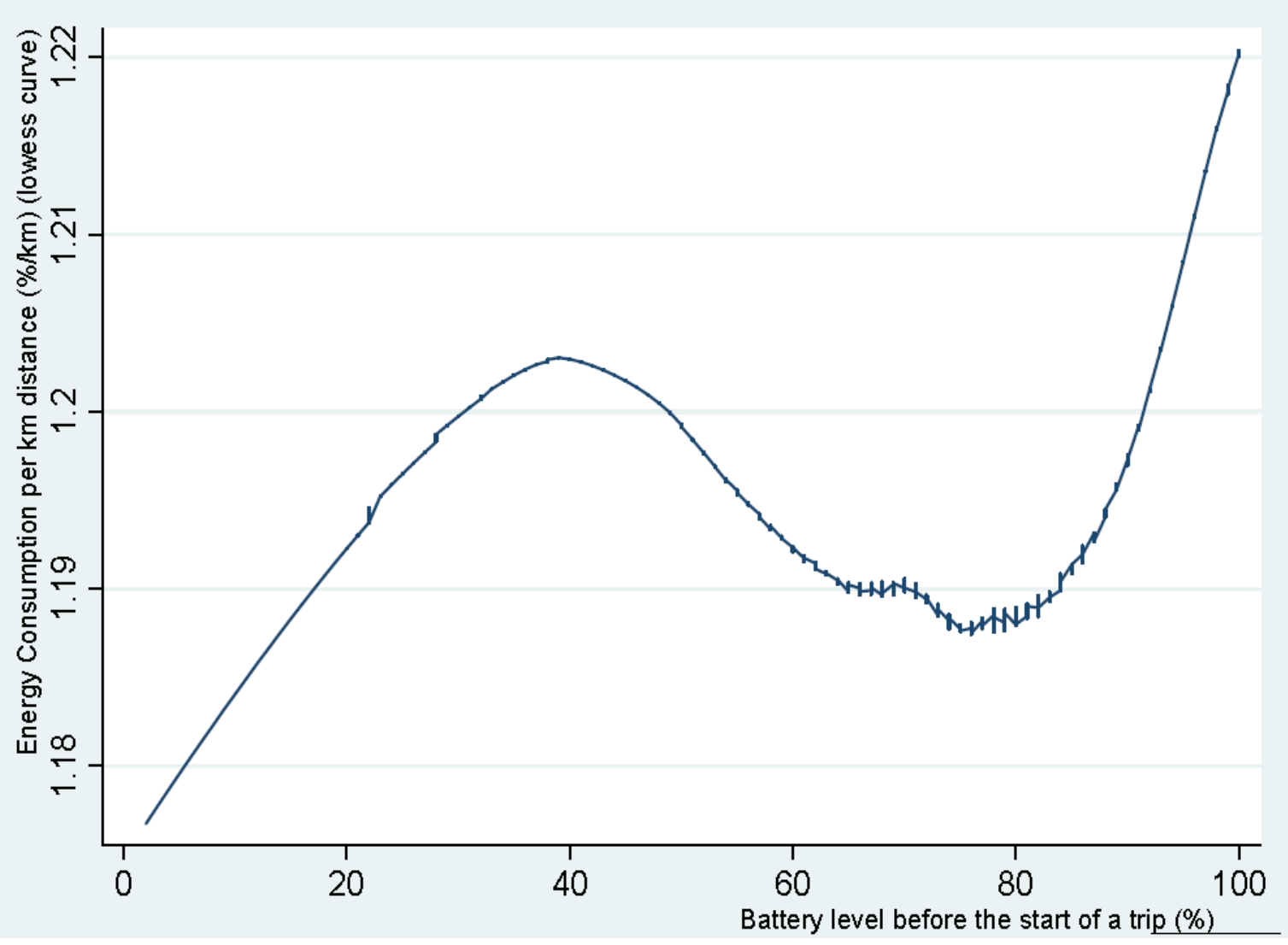

Figure 5. Rate of energy consumption (in percentage) with respect to the initial battery charge level 


\section{Conclusions}

The current study proposes the analysis of the ECR and the factors that affect its variation by harnessing big data from a variety of sources. The study is innovative in its investigation of a very large number of vehicles, number of trips (over 230,000) and km travelled (about 2.3 million), and a great number of sources of information concerning vehicles, roads, weather and seasons. Moreover, the study is novel in its proposition of a model for disentangling the effects of different factors on the ECR of BEVs.

The findings from this study provide insight into the actual energy efficiency of BEVs. The overall mean ECR is equal to $0.183 \mathrm{KWh} / \mathrm{km}$, which for a traditional battery capacity of 16 KWh of a Citroen C-Zero corresponds to a mean driving range of about $87 \mathrm{~km}$, far less than the driving range of $130 \mathrm{~km}$ reported by the manufacturer or the $150 \mathrm{~km}$ set at the European Driving Test. The consumption of electricity is significantly higher in winter, as the ECR increases by about $34 \%$ with respect to summer conditions, which for countries with longer (shorter) winters implies a lower (higher) driving range. Most relevantly, the findings from the calculation of the ECR allow understanding where the price of electricity should be for consumers to have convenience from an energy cost perspective of purchasing a BEV rather than a conventional car.

The most significant findings from this study provide insight into the effect of several variables on the ECR variation. Remarkably, several variables have quadratic or polynomial effects. This appears logical for example for temperature, given that more energy needs to be spent to warm the vehicle at lower temperatures and to cool it down at higher temperatures, and for speed, given that more energy requires to be spent to move the vehicle from lower speeds and to maintain higher driving regimes. Optimal values for the temperature at $14{ }^{\circ} \mathrm{C}$ and for the 
driving speed at about $52 \mathrm{~km} / \mathrm{h}$ are found from the model estimation results, and these are on the one hand good indicative values for potential consumers of BEVs who might want to maximize the use of their battery and hence their vehicle. Interestingly, the battery charge level at the beginning of the trip has a polynomial effect that indicates how the battery level decreases drastically for full charge rather than for lower charge levels, and these are on the other hand not so good indicative values for potential customers of BEVs who might want not to take chances given anxiety about the performance of the vehicles.

The results from this study could be used in order to reflect about possible changes in test cycles for BEVs by regulatory authorities in various countries. In the future, driving ranges could be calculated on the basis of realistic driving cycles so that the values shown in marketing material and displayed on vehicles would be actually reflective of what consumers will experience in the real world. Moreover, the results from this study could be used in order to perform a cost-benefit analysis of the introduction of BEVs under different market penetration scenarios. This would allow to estimate more accurately the level of emissions of BEVs in comparison with conventional vehicles (while accounting the emissions related to the charging), and to predict more precisely the driving range of BEVs that causes the anxiety hindering most consumers to prefer BEVs over conventional vehicles. Specifically, the results indicate that optimal driving speed and acceleration within given weather conditions can be selected by consumers in order to have energy efficient vehicles guaranteeing to reach the destination without the need for recharging.

\section{Acknowledgments}

The authors gratefully acknowledge the comments from anonymous reviewers and the financial support from the ForskEL program of the Danish Ministry for Climate and Energy, the 
technical support of Morten Aabrink for data setting, and Clever A/S and DMI for providing the data.

\section{References}

Alessandrini, A., Cattivera, A., Filippi, F., Ortenzi, F., 2012. Driving style influence on car CO2 emissions. Proceedings of the $20^{\text {th }}$ International Emission Inventory Conference, Tampa, FL.

Alvarez, R., Weilenmann, M., 2012. Effect of low ambient temperature on fuel consumption and pollutant and $\mathrm{CO} 2$ emissions of hybrid electric vehicles in real-world conditions. Fuel, 97, 119-124.

Banjac, T., Trenc, F., Katrašnik, T., 2009. Energy conversion efficiency of hybrid electric heavyduty vehicles operating according to diverse drive cycles. Energy Conversion and Management, 50, 2865-2878.

Ben-Chaim, M., Shmerling, E., Kuperman, A., 2013. Analytic modeling of vehicle fuel consumption. Energies, 6, 117-127.

Birrell, S., McGordon, A., Jennings, P., 2014. Defining the accuracy of real-world range estimations of an electric vehicle. Proceedings of the 17th International Conference on Intelligent Transportation Systems, Qindgao, China, pp. 2590-2595.

Brundell-Freij, K., Ericsson, E., 2005. Influence of street characteristics, driver category and car performance on urban driving patterns. Transportation Research Part D: Transport and Environment, 10, 213-229.

Duke, M., Andrews, D., Anderson, T., 2009. The feasibility of long range battery electric cars in New Zealand. Energy Policy, 37, 3455-3462. 
Egbue, O., Long, S., 2012. Barriers to widespread adoption of electric vehicles: An analysis of consumer attitudes and perceptions. Energy Policy, 48, 717-729.

El-Shawarby, I., Ahn, K., Rakha, H., 2005. Comparative field evaluation of vehicle cruise speed and acceleration level impacts on hot stabilized emissions. Transportation Research Part D: Transport and Environment, 10, 13-30.

Ericsson, E., 2001. Independent driving pattern factors and their influence on fuel-use and exhaust emission factors. Transportation Research Part D: Transport and Environment, 6, 325-345.

Fontaras, G., Pistikopoulos, P., Samaras, Z., 2008. Experimental evaluation of hybrid vehicle fuel economy and pollutant emissions over real-world simulation driving cycles. Atmospheric Environment, 42, 4023-4035.

Fosgerau, M., 2005. Speed and income. Journal of Transport Economics and Policy, 39, 225240.

Fotouhi, A., Yusof, R., Rahmani, R., Mekhilef, S., Shateri, N., 2014. A review on the applications of driving data and traffic information for vehicles’ energy conservation. Renewable and Sustainable Energy Reviews, 37, 822-833.

Heide, C.H., Mohazzabi, P., 2013. Fuel economy of a vehicle as a function of airspeed: the concept of parallel corridors. International Journal of Energy and Environmental Engineering, 4, 28.

Hu, J., Wu, Y., Wang, Z., Li, Z., Zhou, Y., Wang, H., Bao, X., Hao, J., 2012. Real-world fuel efficiency and exhaust emissions of light-duty diesel vehicles and their correlation with road conditions. Journal of Environmental Sciences, 24, 865-874. 
Huo, H., Yao, Z., He, K., Yu, X., 2011. Fuel consumption rates of passenger cars in China: Labels versus real-world. Energy Policy, 39, 7130-7135.

Jensen, A.F., Cherchi, E., Mabit, S.L., 2013. On the stability of preferences and attitudes before and after experiencing an electric vehicle. Transportation Research Part D: Transport and Environment, 25, 24-32.

Kihm, A., Trommer, S., 2014. The new car market for electric vehicles and the potential for fuel substitution. Energy Policy, 73, 147-157.

Kono, T., Fushiki, T., Asada, K., Nakano, K., 2008. Fuel consumption analysis and prediction model for eco route search. Proceedings of the 15th World Congress on Intelligent Transport Systems, New York, NY.

Lohse-Busch, H., Duoba, M., Rask, E., Stutenberg, K., Gowri, V., Slezak, L., Anderson, D., 2013. Ambient temperature $\left(20^{\circ} \mathrm{F}, 72^{\circ} \mathrm{F}\right.$ and $\left.95^{\circ} \mathrm{F}\right)$ impact on fuel and energy consumption for several conventional vehicles, hybrid and plug-in hybrid electric vehicles and battery electric vehicle. SAE Technical Paper 2013-01-1462, doi:10.4271/2013-01-1462..

Mellios, G., Hausberger, S., Keller, M., Samaras, C., Ntziachristos, L., 2011. Parameterisation of Fuel Consumption and CO2 Emissions of Passenger Cars and Light Commercial Vehicles for Modelling Purposes. European Commission Joint Research Centre, Institute for Energy and Transport, Ispra, Italy.

Nam, E.K., Giannelli, R., 2005. Fuel Consumption Modeling of Conventional and Advanced Technology Vehicles in the Physical Emission Rate Estimator (PERE). U.S. Environmental Protection Agency, Washington, D.C. 
Nesamani, K.S., Subramanian, K.P., 2006. Impact of real-world driving characteristics on vehicular emissions. JSME International Journal Series B, 49, 19-26.

United States Environmental Protection Agency, 2014. Fuel Economy Guide. Available at: http://www.epa.gov/fueleconomy/, Washington, D.C.

Wang, H., Fu, L., Zhou, Y., Li, H., 2008. Modelling of the fuel consumption for passenger cars regarding driving characteristics. Transportation Research Part D: Transport and Environment, 13, 479-482.

Wooldridge, J.M., 2010. Econometric Analysis of Cross Section and Panel Data. MIT Press, Cambridge, MA.

Wu, X., Freese, D., Cabrera, A., Kitch, W.A., 2015. Electric vehicles’ energy consumption measurement and estimation. Transportation Research Part D: Transport and Environment, 34, 52-67.

Yao, Z., Wang, Q., He, K., Huo, H., Ma, Y., Zhang, Q., 2007. Characteristics of real-world vehicular emissions in Chinese cities. Journal of the Air \& Waste Management Association, 57, 1379-1386.

Zahabi, S.A.H., Miranda-Moreno, L., Barla, P., Vincent, B., 2014. Fuel economy of hybridelectric versus conventional gasoline vehicles in real-world conditions: A case study of cold cities in Quebec, Canada. Transportation Research Part D: Transport and Environment, 32, 184-192. 